\title{
CARACTERIZACIÓN FÍSICO-QUÍMICA, MICROSCÓPICA DE BARRIDO Y DISPERSIÓN DE RAYOS X DEL MUCÍLAGO DE CLADODIOS DE Opuntia ficus indica EN LA REGIÓN ALTA DE TACNA
}

\author{
Juan José Vargas Mamani ${ }^{a}$, Gabriela Victoria Vera Vargas ${ }^{a}$, \\ Nicole Andrea Suppé Tejada ${ }^{a}$
}

\begin{abstract}
RESUMEN
Este estudio tiene como objetivo describir algunas de las características del mucílago (polímero) de nopal, procedente de la planta Opuntia ficus indica cultivada en el distrito de Sijatara, para dicho fin primero se extrajo el mucilago y se transformó en un polvo seco por el método de choque térmico y precipitación en alcohol. El análisis del polvo seco se hizo por el método de microscopia de barrido y dispersión de rayos x obteniéndose la composición elemental del mucílago, seguidamente se observó en la imagen una superficie rugosa y porosa la cual nos permite observar una gran capacidad de absorción de agua e hinchamiento debido a su rugosidad y porosidad. La caracterización físico química consta de un análisis de prueba de hinchamiento, contenido de cenizas, $\mathrm{pH}$, contenido de ácidos urónicos y solubilidad. Se complementó los análisis incluyendo cromatografía de capa fina el cual probo la ausencia de alcaloides, flavonoides, taninos y terpenos, además de un análisis por el método Kjeldahl, nos indica una leve presencia de proteínas.
\end{abstract}

Palabras clave: Opuntia ficus indica, mucílago, cladodio

\section{PHYSICAL-CHEMICAL CHARACTERIZATION, MICROSCOPIC SWEEPING AND X-RAY DISPERSION OF CLASSY MIXED BY Opuntia ficus indica IN THE HIGH REGION OF TACNA}

\begin{abstract}
The object of this study is to describe some of the characteristics of the mucilage (polymer) of nopal, which originates from the Opuntia ficus plant cultivated in the district of Sitajara. To accomplish the study the mucilage was first dried into a dust through the method of thermic shock and precipitation in alcohol. The dry dust was analyzed through microscopic scanning and the dispersion of $\mathrm{X}$ rays, through which the elemental composition of the mucilage was obtained. Consecutively, a rough and porous surface appeared in the image which permitted us to observe a great capacity of water absorption and enlargement due to

\footnotetext{
a Facultad de Ciencias de la Salud, Universidad Nacional Jorge Basadre Grohmann, Av. Miraflores s/n, Tacna, Perú,ogiva64@gmail.com, victorious7005059@gmail.com.
} 
the roughness and porousness. The physiochemical characterization consists of an analysis of testing the enlargement, ash contents, $\mathrm{pH}$, amount of uranic acid, and solubility. This analysis was complimented by the inclusion of fine cap chromatography, which confirmed the absence of alkaloids, flavonoids, tannins and terpenes; in addition to an analysis with the Kjeldahl method which indicates a slight presence of proteins.

Key words: Opuntia ficus indica, mucilage, cladode

\section{INTRODUCCIÓN}

El nopal es una cactácea, un arbusto que mide de 0,6-1 $\mathrm{m}$ de altura, densamente poblado de ramas. Posee tallos carnosos, áfilos con espinas, ramificados lateralmente de forma ovoide de $15-30 \mathrm{~cm}$ de largo y $13-21 \mathrm{~cm}$ de ancho, aplanados lateralmente, espinas una más grande que las otras de 3,6 espinas y flores solitarias sésiles. Crece en las laderas rocosas desde los $3100-3600 \mathrm{~m}$ de altitud ${ }^{1}$.

También denominada tuna o higo de la India es una planta centroamericana aclimatada en nuestro país. Las ramas son articuladas carnosas y provistas de hojas rudimentarias y caducas en su juventud; más tarde están remplazadas por pelos y espinas. Las flores son amarillentas, con un número de piezas florales indeterminadas. El ovario es unilocular. El fruto conocido bajo el nombre de tuna, es una baya ovoidea, rojiza y comestible ${ }^{2}$.

La planta de nopal posee hojas carnosas llamadas cladodios, los cuales en su interior contienen el mucílago, se designa como mucilagos a las macromoléculas osídicas que se disuelven más o menos en contacto con el agua para formar disoluciones coloidales o geles. En la actualidad se maneja otros términos como hidrocoloides vegetales o polisacáridos vegetales que hacen referencia al mucílago ${ }^{3}$.

Los mucílagos son análogos por su composición y sus propiedades a las gomas; dan con el agua disoluciones viscosas o se hinchan en ella para formar una pseudodisolución gelatinosa. Se encuentran en las algas, en ciertos hongos, en los esfagnos y en muchos vegetales. Por oxidación dan ácido múcico y por hidrolisis, hexosas y pentosas ${ }^{4}$.

\section{PARTE EXPERIMENTAL}

\section{Muestra}

La especie vegetal Opuntia ficus indica, "penca, pala o nopal", fue recolectada en el distrito de Sitajara ( $70^{\circ} 08^{\prime} 02.67^{\prime}$ ') en la provincia de Tarata en el departamento de Tacna a $3155 \mathrm{msnm}$ en el mes de mayo 2018, durante la época de la postcosecha. La clasificación taxonómica de la planta se realizó en el herbario de la Facultad de Ciencias Agrícolas de la Universidad Nacional Jorge Basadre Grohmann por la Magister Rosario Zegarra. La muestra fue usada en fresco, ya que se extrajo pulpa fresca la cual fue tratada directamente. 


\section{Extracción de mucílago}

Fueron evaluados dos métodos para la extracción de mucílago, el primero con choque térmico y el segundo prescindiendo de él, para encontrar las mejores condiciones de extracción. Se decidió usar el choque térmico.

Primero se pelaron los cladodios para obtener la médula, luego cortarla en pedazos más pequeños. Posteriormente se sometió a agua hirviendo, después se introdujo en agua fría (choque térmico) los trozos de mucílago fueron trasladados a una licuadora y a continuación se filtró el preparado. Terminado el proceso el mucílago de consistencia viscosa fue precipitado en alcohol de $96^{\circ}$ para ser escurrido, seguidamente secado a $90^{\circ}$ en una estufa. Después de 24 $\mathrm{h}$, el mucílago seco fue fragmentado y pulverizado en una moledora manual marca Corona. Los fragmentos molidos fueron cernidos en una malla, número $100 \mathrm{y}$ envasados en un frasco de vidrio con tapa hermética ${ }^{5}$.

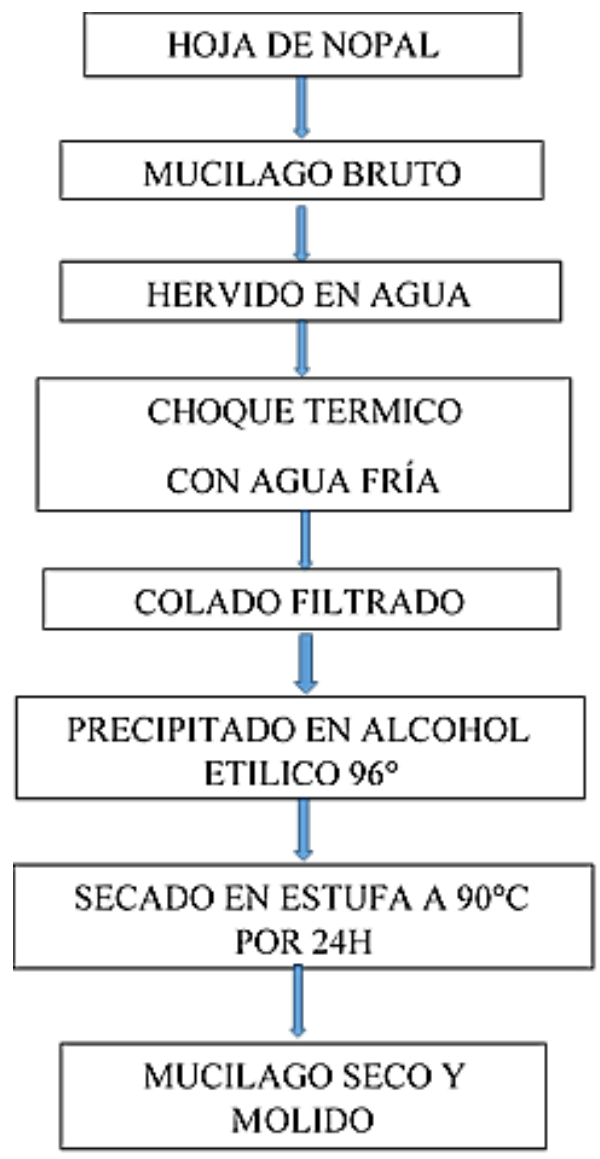

Figura 1. Esquema de método de obtención de mucílago del nopal. 


\section{Composición centesimal de mucílago por microscopia electrónica de barrido SEM y EDX.}

El microscopio electrónico usado es marca TESCAN y modelo VEGA 11 LMU, utiliza un filamento de tungsteno y un microanalizador marca OXFORD y modelo INCA PentaF'ETx3, el voltaje de aceleración va de $200 \mathrm{Va} 30 \mathrm{KV}$, con un aumento continuo de $4 \mathrm{x}$ a $1000000 \mathrm{x}$, es un equipo que permite la observación de la superficie de materiales.

Se tomó una muestra de polvo de mucílago y se colocó en la respectiva matriz metálica con una superficie adhesiva, previamente secada, el polvo así obtenido se adhiere a la superficie, se coloca dentro del microscopio y se somete a vacío, procediendo luego a los análisis programados.

\section{Prueba de hinchamiento}

Se realizó pesando $1 \mathrm{~g}$ de mucílago seco, sumergido en $100 \mathrm{ml}$ de agua destilada en un vaso de precipitados y se dejó reposar por un lapso de $24 \mathrm{~h}$, terminado el tiempo se procedió a pesar el mucílago, previo filtrado. Para luego ser pesado nuevamente y se calculó la diferencia de peso de manera similar. Basado en el método de Ovando Franco ${ }^{7}$.

\section{Contenido de cenizas}

Se procedió a pesar una muestra seca de mucílago molido en una cantidad de un $1 \mathrm{~g}$ en un vaso de crisol para luego someterlo al Horno Mufla a $600 \mathrm{C}^{\circ}$ por un lapso de $8 \mathrm{~h}$, terminado el proceso fue pesado nuevamente. Se hicieron los cálculos por diferencia de peso ${ }^{8}$.

\section{Medición de pH}

El método se basa en medir el $\mathrm{pH}$ a través del siguiente procedimiento, tres soluciones diferentes en fiolas de $100 \mathrm{ml}$ al $8 \%, 4 \%$ y $1 \%$. Posteriormente, lo colocamos en un vaso de precipitados y medimos su $\mathrm{pH}$ en el equipo $\mathrm{pH}$ metro digital ${ }^{9}$.

\section{Cálculo de ácidos urónicos}

El cálculo se realizó por titulación de una solución al $1 \%$ de mucílago, con una solución de hidróxido de sodio $0,1 \mathrm{M}$ usando como indicador fenolftaleína. Se usó como referencia el ácido glucurónico como el monómero de mayor presencia en la cadena polimérica del mucílago y que le otorga sus características ácidas.

\section{Pruebas de solubilidad}

Se coloca $0,1 \mathrm{~g}$ de mucílago en cada tubo de ensayo de $5 \mathrm{ml}$ y en cada uno diferentes solventes (agua destilada, etanol $96^{\circ}$, ciclo hexano, alcohol N-propílico y éter de petróleo.

\section{Contenido de metabolitos secundarios}

Se usó el método de cromatografía en capa fina usando como fase móvil metanol y como reactivo revelador una mezcla de vainillina y ácido sulfúrico Et Oh (5\%), en una cámara cerrada10. 


\section{Contenido de proteínas por el método Kjeldahl}

Se usó el protocolo Método Kjeldahl, A.O.A.C Official Methods of Analysis 13 th Edition, 1984.

\section{RESULTADOS Y DISCUSIÓN}

\section{Mucílago obtenido y procesado}

El mucílago obtenido después del procesamiento tuvo el aspecto de un polvo color mostaza, el rendimiento en porcentaje respecto a una hoja de nopal fue de $0,8235 \% \mathrm{p} / \mathrm{p}$ el cual se envasó en un frasco de tapa hermética, antes de envasarlo se cernió por una malla número 100.

\section{Composición centesimal de mucílago por dispersión de rayos $\mathbf{x}$}

En la figura 2 podemos apreciar el espectro de energía por dispersión de rayos X, y sus subsecuentes resultados semi-cuantitativos en cuanto a los elementos encontrados, observándose que el carbono y el oxígeno son los elementos predominantes, es de entender ya que en las estructuras moleculares de los azúcares predominan estos elementos.

Tabla 1. Resultados del análisis elemental por dispersión de rayos x sobre el mucílago en polvo.

\begin{tabular}{lll}
\hline Element & Weight\% & Atomic\% \\
\hline $\mathrm{C}$ & 45,23 & 53,67 \\
$\mathrm{O}$ & 50,01 & 44,55 \\
$\mathrm{Mg}$ & 0,34 & 0,20 \\
$\mathrm{~K}$ & 0,58 & 0,21 \\
$\mathrm{Ca}$ & 3,84 & 1,36 \\
Totals & 100,00 & \\
\hline
\end{tabular}

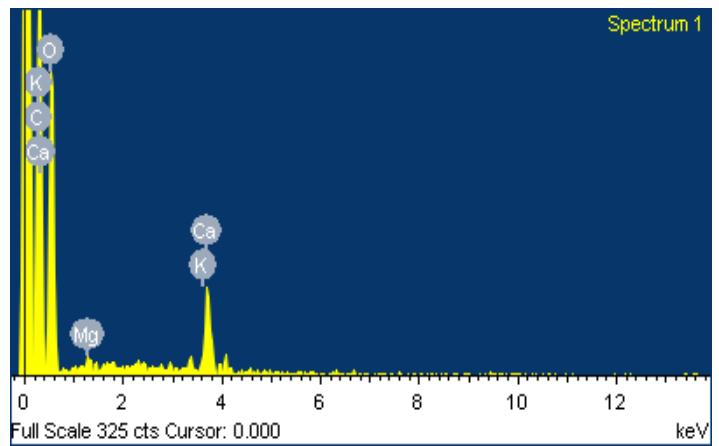

Figura 2. Resultados y porcentajes de análisis elemental por dispersión de rayos X de mucílago en polvo. 


\section{Imágenes SEM (Scanning Electron Microscope)}

En la figura 3 se puede observar unas partículas de mucílago en polvo con un aumento de x 50 se observa terrones granulosos y porosos de aspecto amorfo y en (b) se observa la superficie de una de esas partículas donde se observa una superficie amorfa producto de la contracción del polímero de nopal, con abundantes muescas y cráteres.

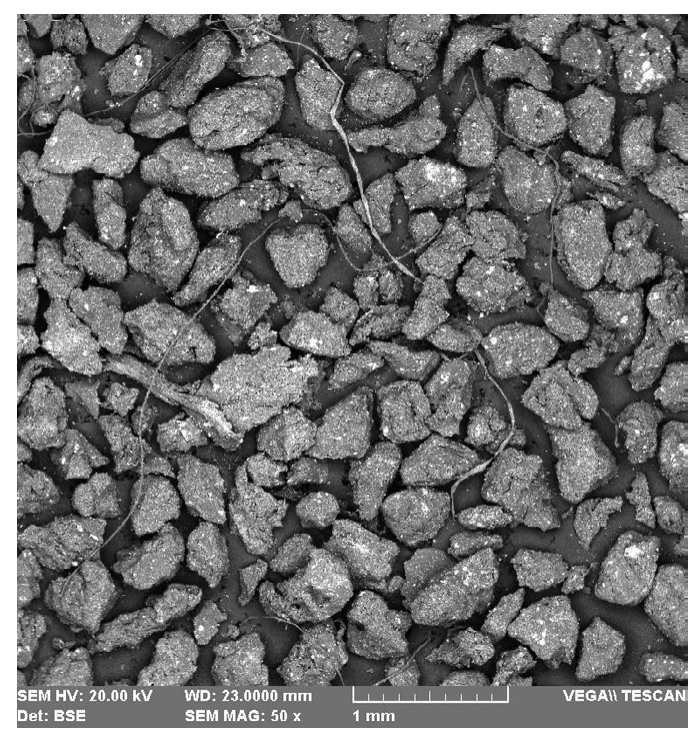

Figura 3. Imagen SEM ampliación x 50 de partículas de mucílago

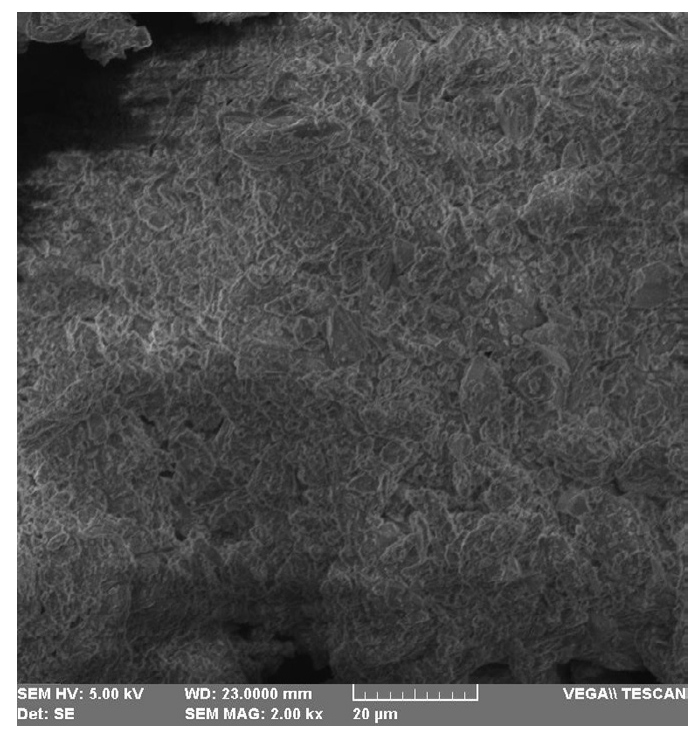

Figura 4. Imagen SEM ampliación x 2000 de partículas de mucílago. 


\section{Prueba de hinchamiento}

En la tabla 2 se puede observar que a un tiempo de 48 horas llega a un máximo de absorción de agua de aproximadamente 12,26 veces su peso o de aproximadamente $13 \mathrm{ml}$ agua por gramo de mucilago seco, es una gran cantidad de agua debido a la abundancia de grupos alcohol del mucílago y el cual produce muchos enlaces puentes de hidrógeno.

Tabla 2. Resultados de prueba de hinchamiento del mucílago.

\begin{tabular}{|c|c|c|c|c|c|c|}
\hline Periodo & $\begin{array}{l}\text { Peso } \\
\text { inicial } \\
\text { (mucílago) }\end{array}$ & $\begin{array}{l}\text { Peso final } \\
\text { (mucílago } \\
+ \text { agua) }\end{array}$ & $\begin{array}{l}\text { Diferencia } \\
\text { (absorción } \\
\text { de agua } \\
\text { del } \\
\text { mucilago) }\end{array}$ & $\begin{array}{l}\text { Absorción } \\
\text { respecto } \\
\text { al peso } \\
\text { inicial de } \\
\text { mucilago } \\
*\end{array}$ & $\begin{array}{l}\% \text { de } \\
\text { hinchamiento }\end{array}$ & Promedio \\
\hline \multirow[t]{3}{*}{$24 \mathrm{~h}$} & $1,26 \mathrm{~g}$ & $10,94 \mathrm{~g}$ & $9,68 \mathrm{~mL}$ & 8.68 & 768,2539 & \\
\hline & $1,22 \mathrm{~g}$ & $13 \mathrm{~g}$ & $11,78 \mathrm{~mL}$ & 10,65 & 965,5737 & \\
\hline & $1,21 \mathrm{~g}$ & 11,6 & $10,39 \mathrm{~mL}$ & 9,58 & 858,6776 & 864,1720 \\
\hline \multirow[t]{3}{*}{$48 \mathrm{~h}$} & $1,26 \mathrm{~g}$ & 15,82 & $14,56 \mathrm{~mL}$ & 12,55 & 1155,5555 & \\
\hline & $1,22 \mathrm{~g}$ & 19,53 & $18,31 \mathrm{~mL}$ & 16,00 & 1500,8196 & \\
\hline & $1,21 \mathrm{~g}$ & 14,83 & $13,62 \mathrm{~mL}$ & 12,26 & 1125,6198 & 1260,6649 \\
\hline
\end{tabular}

\footnotetext{
*Los números se refieren a cuantas veces respecto al peso inicial del polvo aumenta por absorción del agua. Por ejemplo, en la última muestra a $48 \mathrm{~h}$ la absorción fue de 12,26 veces su peso inicial
}

\section{Contenido de cenizas}

En la tabla 3 se puede apreciar el contenido de cenizas del mucílago seco nos indica una gran cantidad de cenizas que nos da una idea de gran cantidad de materia inorgánica que como en el análisis elemental se observa contiene una cantidad apreciable de $\mathrm{K}$, Ca y $\mathrm{Mg}$.

Tabla 3. Resultados de prueba de cenizas.

\begin{tabular}{lllllll}
\hline Crisol & Peso (g) & Mucílago (g) & Cenizas (g) & $\begin{array}{l}\text { \% } \\
\text { cenizas }\end{array}$ & de & Media \\
& & & & 10,2512 & \\
I & 25,0896 & 1,0028 & 0,1028 & 10,8055 & \\
II & 24,4729 & 1,0689 & 0,1155 & 10,6039 & 10,5535 \\
III & 24,2630 & 1,0100 & 0,1071 & & \\
\hline
\end{tabular}




\section{pH y acidez}

La tabla 4 nos muestra que el mucílago disuelto en agua tiene un $\mathrm{pH}$ ácido debido a los ácidos glucurónicos contenidos en una cantidad de $14 \%$, calculados mediante titulación con $\mathrm{NaOH}$.

Tabla 4. Resultados de prueba de $\mathrm{pH}$. Después de esperar un par de minutos el $\mathrm{pH}$ metro.

\begin{tabular}{lll}
\hline $\begin{array}{l}\text { Solución con \% } \\
\text { de mucílago }\end{array}$ & $\mathrm{pH}$ & Temperatura \\
\hline $1 \%$ & 5,450 & $26,1^{\circ} \mathrm{C}$ \\
$4 \%$ & 5,270 & $27,0^{\circ} \mathrm{C}$ \\
$8 \%$ & 5,225 & $24,1^{\circ} \mathrm{C}$ \\
Media & 5,315 & $25,7^{\circ} \mathrm{C}$ \\
\hline
\end{tabular}

\section{Ácidos glucurónicos}

La titulación de acidez de la solución de mucílago nos indica que este tiene un 14,2008 \% de ácidos glucurónicos, lo cual explica la acidez de la sustancia.

\section{Resultados de solubilidad}

La solubilidad del mucílago es más soluble en agua y soluciones ácidas débiles, pero en solventes orgánicos y alcoholes provocan deshidratación del mucílago por lo que lo precipitan.

Tabla 5. Resultados de pruebas de solubilidad del mucílago.

\begin{tabular}{ll}
\hline SOLVENTE & RESULTADOS \\
\hline Agua destilada & Soluble \\
Etanol 96 $^{\circ}$ & Insoluble \\
Alcohol N-propílico & Insoluble \\
Ciclo hexano & Insoluble \\
Ácido acético 5\% & Parcialmente soluble \\
Éter de petróleo & Insoluble \\
\hline
\end{tabular}

\section{Metabolitos secundarios y proteínas}

En la tabla 6 podemos apreciar que los análisis cromatográficos revelan ausencia de metabolitos secundarios pero una pequeña cantidad de proteínas en el mucílago. 
Tabla 6. Resultados de análisis cromatográficos y Kjeldahl del mucílago.

\begin{tabular}{lc}
\hline \multicolumn{1}{c}{ ANÁLISIS } & RESULTADO \\
\hline DETERMINACIÓN DE PROTEÍNAS (\%) & 1,80 \\
Método Kjeldahl, A.O.A.C Official Methods of Analysis 13 & \\
th Edition, 1984 & \\
DETERMINACIÓN DE METABOLITOS SECUNDARIOS & $\begin{array}{c}\text { Negativos a terpenos, } \\
\text { flavonoides, lactonas } \\
\text { Metodología thin layer chromatography (TLC) }\end{array}$ \\
\end{tabular}

\section{CONCLUSIÓN}

El rendimiento de mucílago obtenido es de $0,8235 \% \mathrm{p} / \mathrm{p}$, las fotografías SEM mostraron que el mucílago seco tiene abundancia de surcos, prominencias y poros en una superficie amorfa, la composición centesimal del mucílago comprende: C (45,02\%); O (51,09\%); $\mathrm{Mg}(0,25 \%) ; \mathrm{S}(0,17 \%) ; \mathrm{K}(0,47 \%)$ y Ca $(3 \%)$. Los análisis físico-químicos arrojaron los siguientes resultados: el $\mathrm{pH}$ es de 5,3 , las cenizas son de $10,55 \%$, la prueba de hinchamiento del mucílago seco probó su gran capacidad de absorción de agua siendo lo máximo a las $48 \mathrm{~h}$ de 12,26 veces su peso respecto al inicio. El análisis Kjeldahl revela un pequeño contenido de proteínas de alrededor de $1,8 \%$. El análisis por cromatografía de capa fina probó la ausencia de terpenos, flavonoides, lactonas sesquiterpénicas, alcaloides y taninos, esto prueba que el mucílago extraído está exento de otros metabolitos lo que prueba su pureza. La ausencia de metabolitos extraños, su gran capacidad de absorción de agua, consistencia mucilaginosa, su carácter ácido y alto contenido de oxígeno y carbono, nos hace llegar a la conclusión de que el mucílago obtenido es un polímero de azúcares con características ácidas.

\section{AGRADECIMIENTO}

Se agradece a la Mgr. Mercedes Velarde de la I.E.P Colegio Santa Ana de Tacna por impulsar a desarrollar este trabajo de investigación, también agradecemos a la Universidad Jorge Basadre Ghroman por darnos el apoyo mediante el programa RSU por intermedio del Ing. Edgar Talla. Por último, agradecemos al Ing. Julián Nieto, de la Facultad de Metalurgia, por su apoyo de parte del Laboratorio de Microscopia Electrónica SEM. 


\section{REFERENCIAS BIBLIOGRÁFICAS}

1. Cáceres CN. Taxonomia y usos Tradicionales de las Plantas Medicinales de la Provincia de Candarave - Tacna. [Tesis de grado]. Tacna (Perú): Universidad Nacional Jorge Basadre Groohmann; 2004.

2. Vidal Jorge. Curso de Botánica. 29ª edición. Lima (Perú). Bruño; 1998.

3. Bruneton J. Farmacognosia Fitoquímica Plantas medicinales. $2^{\mathrm{a}}$ edición. Zaragoza (España): Acribia; 2001.

4. Font Quer P. Diccionario de Botánica. $9^{\circ}$ reimpresión. Barcelona (España): Labor. 1985.

5. Quispe H. Aplicación del mucilago de nopal Opuntia ficus indica en la clarificación del agua del rio Uchusuma. [Tesis de grado]. Tacna: Universidad Nacional Jorge Basadre Grohmman; 2012.

6. Egerton RF. Physical Principles of Electron Microscopy. 2nd. Ed. Basel (Switzerland): Springer; 2016.

7. Ovando M. Modificacion de biopolímero extraido de Nopa (Opuntia ficus indica) y su aplicación para la remosion de metales pesados en agua. [Tesis posgrado]. San Luis Potosí: Instituto Potosino de Investigación científica y Tecnológica AC; 2012.

8. Nielsen S. Análisis de los Alimentos. Zaragoza (España): Acribia; 2007.

9. Shriner R. Identificación sistemática de compuestos orgánicos. 2da. edición. México: Editorial Limusa - Wiley; 2013.

10. Rojas-Molina I, Gutiérrez-Cortez E, Bah M, Rojas-Molina A, Ibarra-Alvarado C, Rivera-Muñoz E, et al. Characterization of calcium compunds in Opuntia ficus indica as a source of Calcium for Human Diet. [Internet]. J Chem. 2015; Article ID 710328. doi: 10.1155/2015/710328. [citado 12 abril de 2019]. Disponible en: https://www.hindawi. com/journals/jchem/2015/710328/cta/ 